\title{
Do You Know People Who Feign? Proxy Respondents About Feigned Symptoms
}

\author{
Brechje Dandachi-FitzGerald ${ }^{1} \cdot$ Harald Merckelbach $^{2}$ (D) $\cdot$ Irena Bošković $^{3} \cdot$ Marko Jelicic $^{2}$
}

Received: 3 March 2020 / Accepted: 22 July 2020 / Published online: 18 August 2020

(C) The Author(s) 2020

\begin{abstract}
We asked students, clinicians, and people from the general population attending a public university lecture $(n=401)$ whether they knew others who (had) feigned symptoms. We also asked about the type of symptoms and the motives involved. A slight majority of proxy respondents (59\%) reported that they knew a person who (had) feigned symptoms, and $34 \%$ knew a person who had admitted to them having feigned symptoms. According to our respondents, the most often feigned symptoms were headache/migraine, common cold/fever, and stomachache/nausea, and the most important reasons for doing so were sick leave from work, excusing a failure, and seeking attention from others. We conclude that feigning is part of the normal behavioral repertoire of people and has little to do with deviant personality traits and/or criminal motives. Also, the current emphasis in the neuropsychological literature on malingering, i.e., feigning motivated by external incentives, might be one-sided given that psychological motives, notably seeking attention from others and excuse making, seem to be important determinants of everyday feigning.
\end{abstract}

Keywords Feigning $\cdot$ Prevalence $\cdot$ Malingering $\cdot$ DSM-5 $\cdot$ Proxy respondents

The literature on symptom exaggeration is blossoming (Bass \& Halligan, 2014; Bass \& Wade, 2019; Merckelbach et al., 2019; Suchy, 2019). "Malingering" is a frequently employed descriptive to refer to this phenomenon. However, following the convention of the DSM-5 (American Psychiatric Association, 2013), this term is usually reserved for cases in which symptom exaggeration seems to be motivated by an external reward (e.g., obtaining compensation money in a litigation procedure). Several authors have criticized the importance of the external incentive criterion because clinicians cannot easily evaluate the presence of such an incentive (e.g., Berry \& Nelson, 2010; Merten \& Rogers, 2017; Erdodi et al., 2018). And even when clearly present, a link between the external incentive and the examinees' actual

Brechje Dandachi-FitzGerald

B.FitzGerald@maastrichtuniversity.nl

1 Clinical Psychology Section, Maastricht University, Maastricht, The Netherlands

2 Forensic Psychology Section, Maastricht University, Maastricht, The Netherlands

3 Department of Psychology, Erasmus University Rotterdam, Rotterdam, The Netherlands motivation to exaggerate symptoms still has to be established. Indeed, motivations to engage in symptom exaggeration are far more likely to be multifaceted rather than being either purely internal or external (Merten \& Rogers, 2017; Hong, 2019). With these considerations in mind, we prefer the much broader term "feigning" because it encompasses symptom exaggeration that might be motivated by external, but also by internal (e.g., seeking attention or sympathy from others) motives (Chafetz et al., 2019; Young, 2019). Related terms abound in the extant literature on symptom exaggeration, such as response bias, non-authentic or non-credible responding, performance invalidity, and impression management. Compared with feigning these terms are either more neutral as to the direction of symptom distortion (e.g., response bias can refer to both exaggeration and minimization of symptoms), or they are restricted to a certain domain (e.g., performance invalidity refers to exaggeration of impairments on cognitive tests). From a theoretical point of view, these terms are therefore more precise than feigning, but they are rather technical and therefore less optimal as key terms in surveys that include lay people (see below).

Much has been written about the scale on which feigning occurs. An older, once widespread, assumption among clinicians was that feigning illness is extremely rare (Jung, 1903; see for a discussion: Jelicic et al., 2017). This 
assumption has fallen out of grace, and most modern researchers would nowadays subscribe to the idea that feigning occurs on a non-trivial scale. But what, then, does non-trivial mean? Obviously, there is no fixed prevalence because the extant literature makes it plain that rates of feigning are situationally specific. For example, context of testing does matter. Thus, using stand-alone performance validity tests (PVTs) that gauge exaggeration of memory impairments, Jackson et al. (2017) found such exaggeration to be more often present when veterans are tested in an incentivizing context (e.g., clinical evaluations that may impact service-related health care advantages) than when they are tested in a research context $(60 \%$ versus $5.5 \%$ ). Similarly, there are indications that criminal offenders in jail engage more often in symptom exaggeration on a symptom validity test (SVT) than offenders in a forensic psychiatric facility ( $25 \%$ versus $4 \%$, Niesten et al., 2015). Relatively high rates of symptom exaggeration have been reported for individuals who are involved in litigation or workers' compensation procedures. For example, Larrabee et al. (2009) opined that the base rate of feigning in these groups ranges from 30 to $50 \%$. However, this estimate has not gone unchallenged. Reviewing studies on symptom exaggeration in forensic disability-related assessments, Young (2015) proposed the more conservative prevalence range of $0-30 \%$.

Basically, two methods have been used to examine the scale on which feigning occurs. One is with help of PVTs and/or SVTs that are administered to specific patient groups (e.g., veterans with psychological problems, forensic psychiatry inmates, litigating patients). Many of the articles cited above relied on such instruments. The advantage of this approach is that these instruments often possess high sensitivity and specificity, allowing for relatively accurate estimates of the prevalence of symptom and/or impairment exaggeration in certain circumstances. However, this approach will inevitably yield variation in base rate estimates across studies due to differences in the accuracy characteristics of the validity tests employed and the criteria adopted to define cases of feigning (e.g., requiring one versus at least two validity tests to be failed; Victor et al., 2009). More importantly, these estimates pertain to highly specific populations (e.g., US military veterans), and are therefore difficult to generalize to other samples (e.g., European patients involved in litigation; see for an example: Plohmann \& Hurter, 2017).

The second approach is asking experts, for example, clinical neuropsychologists and medical experts, to generate estimates of feigning in various groups. The often-cited study of Mittenberg et al. (2002) relied on this approach. These researchers surveyed 131 US neuropsychologists who regularly carried out evaluations in civil or criminal cases. Based on their personal experiences, the experts in the Mittenberg et al. study estimated the base rate of feigning to hover around
$30 \%$ in disability and injury cases and $19 \%$ in criminal cases. Experts felt that the highest levels of feigning are found in cases involving mild head injury complaints $(41 \%)$, chronic fatigue $(39 \%)$, and pain $(34 \%)$. In their survey among European neuropsychologists $(n=515)$, DandachiFitzGerald, Ponds, and Merten (2013) found that these experts estimated feigning to occur in $4 \%$ of their clinical assessments and $10 \%$ of their forensic assessments. Santamaria et al. (2013) surveyed medical doctors $(n=161)$, most of whom were insurance experts involved in disability assessments. Based on their professional experience, the doctors believed feigning to occur most often in patients with cervical pain, fibromyalgia, chronic pain, depression, and anxiety, with median prevalence percentages for these conditions estimated to be on the order of $50 \%$. A disadvantage of this approach is that experts might not always be accurate in their impression that patients are feigning symptoms. Germane to this is the study of Dandachi-FitzGerald et al. (2017), who compared clinical impressions of neuropsychologists and their patients' performance on a PVT and an SVT. Of the 152 patients for whom neuropsychologists had predicted plausible symptom presentations, 14 patients $(9.2 \%)$ failed on both instruments. Of the 51 patients for whom neuropsychologists had predicted problematic symptom validity, 35 patients $(68.6 \%)$ passed both instruments. In general, research has consistently shown that when clinicians rely on their clinical judgment, they are not very successful in discriminating between genuine and feigned symptom presentations. For example, Heaton, Voght, and Lehman (1978) provided ten neuropsychologists with clinical test profiles of 16 instructed feigners and 16 head-injured patients. The neuropsychologists had to determine for each test profile whether it belonged to a genuinely impaired patient or an instructed feigner. Classification accuracy was generally poor (i.e., detection ranged from chance level to $20 \%$ above chance level). Similarly, a review of 12 studies investigating the ability of medical experts to distinguish between feigned and genuine self-reported symptoms in a clinical consultation, found the detection rate of feigning to range between 0 and 25\% (Rosen \& Philips, 2004; for an overview, see Dandachi-FitzGerald \& Martin, in press). Thus, clinical impressions of feigning are far from perfect.

In the current article, we introduce a third approach to study the scale on which feigning occurs: just asking people whether they know other people who feign or have feigned symptoms. Feigning might be a sensitive topic and hence, directly asking people whether they engage(d) in such behavior might lead to under-reporting. An alternative way of surveying people is provided by what has been called the nominative method, which asks respondents (i.e., proxy respondents) to report on the sensitive behaviors of others (Tourangeau \& Yan, 2007). An advantage of this method is that it allows for a series of follow-up questions (e.g., "why was this person feigning?"; "how do you know that this person was feigning?"), and in 
this way, information may be gathered that supplement findings from SVT/PVT studies and surveys among experts. A disadvantage of the nominative approach is that respondents' judgments, as is true for those of experts, might be based on imprecise intuitions. To some extent, this can be remedied by differentiating between those who say they know a person who feigns/feigned, and those who say that the person in question admitted to them having feigned symptoms. Arguably, the latter subgroup might provide more accurate information about feigning and its background.

\section{Methods}

\section{Sample}

The total sample consisted of 401 people (258 men, 104 women, 4 transgenders, 14 persons who preferred not to indicate their sex, and 21 people who did not fill out the item). There were several subsamples: people from the general public $(n=75$; mean age $=28$ years $)$; students $(n=288$; mean age $=20.8$ years $)$ from either Maastricht University (73\%), the Netherlands, or from Leuven University (27\%), Belgium; insurance doctors in training ( $n=22$; mean age $=30.1$ years); and psychotherapists in training ( $n=16$; mean age $=35.3$ years). Participants were included through convenience sampling. That is, participants from the public and students were approached during lectures about memory or miscarriages of justice. Insurance doctors and psychotherapists ("clinicians") were recruited during lectures and workshops about symptom validity testing. Sample recruitment took place at widely separated geographical areas (Maastricht, the Netherlands; Eindhoven, the Netherlands; Roermond, the Netherlands; Leuven, Belgium). Participants were informed that their data were treated anonymous and confidential. The study was approved by the standing ethical committee of the Faculty of Psychology and Neuroscience of Maastricht University, Maastricht, The Netherlands (198_02_09_2018-V02).

\section{Questionnaire}

We developed a short questionnaire ("Ten Questions About Feigning") than can be easily completed within $10 \mathrm{~min}$ (see Appendix for English version). Thus, using the nominative approach, the questionnaire asked respondents whether they knew other people who feigned symptoms, and if so, how many. Next, respondents were asked to concentrate on the case of feigning they knew best and to answer questions about the type of symptoms that were feigned in that case, why these symptoms were feigned, and how the respondent knew that this was a case of feigning. For the why question, answer options were drawn from the literature on incentives for symptom exaggeration (e.g., Van Egmond \& Kummeling, 2002). Item 6 was about whether respondents did ever feign symptoms themselves, and this item was followed-up by questions about symptoms that respondents would feign and symptoms they would certainly not feign (adapted from Dandachi-FitzGerald \& Merckelbach, 2013). The questionnaire contained both closed questions accompanied by answer options and open questions. The open questions (i.e., item 3, 7, and 9) asked respondents to provide a description of symptoms. For these items, we grouped answers that overlapped into broader categories (e.g., "common cold and/or fever") and tabulated the frequency of these categories.

\section{Results}

Datafile and background information can be found on Dataverse.NL, the open-data platform of Dutch Universities: https:/hdl.handle.net/10411/GJL54W.

\section{Base Rate Estimates}

Across the total sample $(n=401), 238$ respondents (59\%) said that they knew one or more persons who engaged or had engaged in feigning (10\% knew one feigner, $36 \%$ knew between 2 and 5 feigners, and $13 \%$ more than 5 feigners). ${ }^{1}$ The number of respondents who indicated that they themselves had feigned symptoms was significantly lower: $181(45 \%)$, $\chi^{2}(1)=15.67, p<0.01$. In total, 137 respondents (34\%) said that they were certain that a person they knew had feigned symptoms because the person in question had told them so. ${ }^{2}$

\section{Symptoms}

We asked respondents to concentrate on the case of a feigner that they knew best and to write down which particular symptom this person was feigning. Table 1 shows the top five most frequently mentioned symptoms for two groups: the group that said they knew a feigner $(n=238)$, and the more restricted group of those who said a feigner had confessed to them $(n=137)$. Of note, two symptom categories relevant to (neuro)psychologists emerge in the top five: chronic (low back) pain and mental health issues. Depending on how a strict one defines the detection of feigning behavior, between 8 and $19 \%$ of respondents knew a person who had feigned these conditions. Even if one considers the lower bounds of the $95 \%$ confidence intervals, this range is still $6-14 \%$. In the subsample of 39 respondents who said that they knew a person who had feigned mental health

\footnotetext{
${ }^{1}$ Not surprisingly, clinicians (i.e., insurance doctors and psychotherapists) more often said that they knew one or more feigners than students or people from the general public ( $74 \%$ versus $61 \%$ versus $47 \%$ ), $\chi^{2}(2)=9.33, p<0.01$. Given the unequal sample sizes, we do not consider these subgroup differences here any further.

${ }^{2}$ This pertains to item 5 of the questionnaire (see Appendix). Endorsement rates for other answer options were as follows: $52(13 \%)$ respondents said that another person had told them so; 97 (24\%) said that their intuition had told them so; and $83(21 \%)$ felt that the symptoms were not credible.
} 
Table 1 Top five feigned symptoms described by respondents

\begin{tabular}{lrll}
\hline Subgroup & \multicolumn{1}{c}{$n$} & $\%$ of $n=401$ & $95 \%$ CI \\
\hline "Know a feigner" & 238 & $59 \%$ & \\
Headache/migraine & 87 & $22 \%$ & $18-26 \%$ \\
Common cold/fever & 70 & $17 \%$ & $14-22 \%$ \\
Stomachache/nausea & 64 & $16 \%$ & $13-20 \%$ \\
Mental health issues & 39 & $10 \%$ & $7-13 \%$ \\
Chronic (low back) pain & 36 & $9 \%$ & $7-12 \%$ \\
"Feigner confessed" & 137 & $34 \%$ & \\
Common cold/fever & 57 & $14 \%$ & $11-18 \%$ \\
Headache/migraine & 56 & $14 \%$ & $11-18 \%$ \\
Stomachache/nausea & 44 & $11 \%$ & $8-14 \%$ \\
Mental health issues & 16 & $4 \%$ & $3-6 \%$ \\
Chronic (low back) pain & 16 & $4 \%$ & $3-6 \%$ \\
\hline
\end{tabular}

95\% CI 95\% confidence interval

issues, the most frequently mentioned condition was depression (14; 36\%), followed by burn-out $(7 ; 18 \%)$ and post-traumatic stress disorders (PTSD; 5; 13\%). A similar pattern emerged when only respondents were taken into account who had heard from the feigners themselves that they had simulated a mental health problem.

\section{Motives}

Table 2 lists the top five motives that respondents thought were behind the feigning behavior. Respondents could tick several answers options (see Appendix), and so percentages do not add up to $100 \%$. Remarkably, not only external incentives (e.g., sick leave) were in the top five, but also motives

Table 2 Top five motives involved in feigning according to respondents

\begin{tabular}{lrll}
\hline Subgroup & \multicolumn{3}{l}{ n of $n=401$} \\
\hline "Know a feigner" & 238 & $59 \%$ & \\
Sick leave from work & 165 & $41 \%$ & $36-46 \%$ \\
Seeking attention from others & 92 & $23 \%$ & $19-27 \%$ \\
To excuse a failure & 78 & $20 \%$ & $16-24 \%$ \\
Extension of holiday & 50 & $13 \%$ & $10-16 \%$ \\
Social security benefits & 42 & $11 \%$ & $8-14 \%$ \\
"Feigner confessed" & 137 & $34 \%$ & \\
Sick leave from work & 109 & $27 \%$ & $23-32 \%$ \\
To excuse a failure & 49 & $12 \%$ & $9-16 \%$ \\
Seeking attention from others & 43 & $11 \%$ & $8-14 \%$ \\
Extension of holiday & 38 & $10 \%$ & $7-13 \%$ \\
Social security benefits & 19 & $5 \%$ & $3-7 \%$ \\
\hline
\end{tabular}

95\% CI 95\% confidence interval that are more psychological in nature (e.g., excuse making and attention seeking).

\section{What Would You Feign?}

Respondents were asked what condition they would feign when they would simulate a certain symptom. A broad variety of illnesses, impairments, and symptoms were mentioned, but the majority of respondents (64\%) indicated to prefer relatively common conditions such as headache, flu, common cold, stomachache, back pain, and migraine. The reasons for preferring these symptoms are shown in Table 3 (respondents could endorse multiple options and therefore percentages do not add up to $100 \%$ ). The most often mentioned considerations in this respect are that they are easy to feign and that respondents did previously genuinely suffer from these symptoms. A minority $(29 ; 7 \%)$ said that they would feign a mental health problem, mostly depression $(9 ; 2 \%)$, burn-out $(5 ; 1 \%)$, and anxiety disorders/PTSD $(5 ; 1 \%)$.

Respondents mentioned a broad range of symptoms that they would certainly not feign and the most important reasons for avoiding these symptoms were that feigning them was deemed morally unacceptable and/or that these symptoms were difficult to feign.

\section{Discussion}

Most people would argue that being sick is undesirable. Thus, it is a counterintuitive idea that individuals might feign illness. Still, there is a voluminous neuropsychological literature suggesting that feigning occurs on a non-trivial scale in certain groups (Larrabee et al., 2009; but see Young, 2015). This literature stresses the role of financial or legal advantages as determinants of feigned conditions (e.g., mild head injury, PTSD, depression, chronic pain; (e.g., Bianchini, Curtis, and

Table 3 Reasons for preferring or avoiding certain symptoms when feigning

\begin{tabular}{lrl}
\hline Subgroup & $n$ & $\%$ \\
\hline Why would you choose this? & 300 & $75 \%$ \\
Easy to feign & 200 & $50 \%$ \\
Did previously suffer from this & 66 & $17 \%$ \\
Know people who suffer from this & 56 & $14 \%$ \\
May be feigned for a long period & 28 & $7 \%$ \\
Makes a big impression on others & & \\
Why would you avoid this? & 224 & $56 \%$ \\
Morally unacceptable & 194 & $48 \%$ \\
Difficult to feign & 161 & $40 \%$ \\
Probability of detection too high & & \\
\hline
\end{tabular}


Greve, 2006) and is based primarily on findings obtained with PVTs and/or SVTs administered to well-defined groups (e.g., litigating patients; e.g., Plohman \& Hurter, 2017) or surveys among experts (e.g., neuropsychologists; e.g., DandachiFitzGerald et al., 2013; forensic psychiatrists; Cohen \& Appelbaum, 2016).

Less is known about feigning in everyday life and whether it is a common phenomenon. Relying on diverse samples recruited at different locations, the current study surveyed non-clinical respondents about feigning and its motives. Its main findings can be summarized as follows. First, feigning is ubiquitous. Many respondents reported that they knew a person who had feigned symptoms $(59 \%)$ or who had admitted to have feigned symptoms (34\%). Also, $45 \%$ said they had feigned symptoms themselves. Our results are in line with a survey among 39 Swiss lay persons: $41 \%$ of them said they had simulated symptoms in the past in the context of school absenteeism, exemption from military service, sports, or testing (Merten \& Giger, 2018). The relatively high rates of selfadmitted feigning of symptoms/illness in non-clinical samples run counter to the widely voiced view that feigning is a special class of behaviors connected to deviant personality traits such as antisocial features (see, for a critical analysis: Berry \& Nelson, 2010). Rather, they suggest that feigning is part of the normal behavioral repertoire of people.

Second, according to our respondents, the symptoms most often feigned were headache/migraine, common cold/fever, and stomachache/nausea. This fits well with the list of most prevalent symptoms that Petrie et al. (2014) found in their population-based survey. On the other hand, given that students were over-represented in our sample, it is remarkable that feigned dyslexia and attention deficit hyperactivity disorder (ADHD) were mentioned considerably less often than somatic symptoms (see also Bošković, 2019).

Third, the motives that respondents thought to be most important for feigning these conditions were sick leave from work, excusing a failure, and seeking attention from others. This pattern is reminiscent of sociologist Talcott Parsons (1975), who coined the term "sick role" to refer to those people who strive to be labeled sick in order to escape professional, occupational, and domestic issues (see, for an example, Summerfield, 2011). Our findings also suggest that the emphasis in the current neuropsychological literature on malingering (i.e., feigning motivated by external incentives) might be onesided and that psychological motives, notably seeking attention from others and excuse making, are important determinants of everyday feigning (Young, 2019; see also Suhr \& Wei, 2013). Furthermore, most neuropsychological studies on malingering focused on financial incentives, but our results suggest that this is a narrow conceptualization of external motives (see Table 2, but also Van Egmond \& Kummeling, 2002).

Fourth, when respondents were asked what symptoms they would consider to feign, common somatic conditions, such as headache and back pain, were most often mentioned. The preference for these symptoms as targets of feigning accords well with findings from a previous study (Dandachi-FitzGerald \& Merckelbach, 2013). The popularity of common symptoms might be explained by other findings from our survey, namely that people prefer to feign symptoms that are familiar to them, easy to simulate, and morally acceptable.

Taken together, our survey findings suggest that feigning common symptoms is a relatively normal tactic that people may employ when they want to avoid stressful or annoying work, to excuse a failure, or to acquire the attention of others. More generally, our findings support the idea that feigning is a form of adaptive behavior that in itself has little to do with deviant personality features and criminal aspirations (Berry \& Nelson, 2010). This is an important conclusion because it refutes the criminological typology of feigning that is so prominent in the DSM-5 (Niesten et al., 2015). Everyday feigning includes primarily unspectacular symptoms like headache and nausea, and everyday feigners wish to receive a short time benefit/excuse, a pattern that underlines the idea that feigning is quantitatively and qualitatively rather context specific.

Several limitations of our survey deserve comment. First, in our sample, students were over-represented, and people from the general population were under-represented. Thus, our base rates of feigning should be taken with caution. Second, although we collected data at four different sites, there is a remote possibility that our proxy respondents referred to a small group of feigning people that were present in all their networks. More precise estimations of the scale on which feigning occurs can be generated when the social networks of proxy respondents are taken into account and prevalence rates are corrected for overlapping cases (Sirken, 1970). Note, however, that our ambition was not to derive precise point prevalence estimates from our data, but rather to gauge the extent to which everyday feigning occurs. Third, we relied on proxy respondents to avoid under-reporting due to the sensitivity of the topic, but the price paid for this is that proxy responders might be less accurate when it comes to the motives of feigning behavior. Recent research suggests that there are other ways to circumvent under-reporting due to sensitivity and in this context, a survey method known as Bayesian truth serum (BTS) is particularly noteworthy (see for an example: Loughran, Paternoster \& Thomas, 2014). Thus, it might be worthwhile to adapt our short questionnaire for use in a BTS set-up.

Research on feigning sickness might benefit from studies that target feigning behavior in non-clinical and non-forensic samples. Therefore, we encourage researchers to adapt our short questionnaire and employ it in large-scale and population-based surveys. 


\section{Appendix}

\section{Ten questions about feigning}

These questions are about people who feign symptoms in order to obtain a certain benefit. It may be to avoid boring work or a social obligation they don't like. Or they may want to obtain compensation money or disability benefits. There might be many more reasons to feign an illness, disease or symptoms.

1. Do you know people of whom you are certain that they feign or have feigned symptoms/illness? (tick box)

\section{$\square$ Yes}

$\square$ No $\{$ go to question 6 \}

2. How many people do you know who feign or have feigned symptoms/illness? (tick box)

$\square 1$

$\square 2-5$

$\square 6-10$

$\square>10$

3. If you concentrate on the case of a feigning person you know best, what type of symptoms/illness was this person feigning? (give short description):

4. What was this person trying to achieve with the feigning? (tick all relevant boxes)

$\square$ Social security benefits (unemployment, disability or welfare)

$\square$ Private medical insurance money for illness or disability

$\square$ Compensation money

$\square$ Winning a legal procedure

$\square$ Obtaining medication 
$\square$ Sick leave from work or school

$\square$ More liberal academic regulations (e.g., an extra exam possibility)

A waiver of college tuition

$\square$ A waiver of study loan payments

$\square$ Obtaining a personal health budget

$\square$ Reimbursement of medical costs (e.g., plastic surgery)

$\square$ An apartment or house

$\square$ A permit to stay in the country

$\square$ An extension of holidays/extra days off from work

$\square$ To receive attention from others

$\square$ To excuse a failure

$\square$ Something different, namely:

5. How do you know for sure that this was a case of feigning? (tick all relevant boxes)

$\square$ The person him/herself told me

$\square$ Another person told me

$\square$ My intuition told me

$\square$ The symptoms/illness was/were not credible

$\square$ Something different, namely:

6. Did you yourself feign symptoms/illness? (tick box)

$\square$ Yes

$\square$ No

7. Suppose you would decide to feign a symptom/illness, what type of symptom/illness would you select to simulate? (give short description) 
8. Why would you choose this symptom/illness? (tick all relevant boxes)

$\square$ At one time I really suffered from this symptom/illness

$\square$ I know people who really suffer from this symptom/illness

$\square$ This symptom/illness is easy to feign

$\square$ This symptom/illness may be feigned for a prolonged period

$\square$ This symptom/illness makes a big impression on others

$\square$ Something different, namely:

9. Suppose you would decide to feign a symptom/illness, what type of symptom/illness would you certainly not choose to feign? (give short description):

10. Why would you not choose that particular symptom/illness? (tick all relevant boxes).

$\square$ It is difficult to feign this in a convincing way

$\square$ The probability that you are detected is too high

$\square$ It is morally unacceptable to feign this

$\square$ Something different, namely [open text field]

Finally, a few questions about your background

What is your age?

What is your sex?

Female

$\square$ Male

Transgender

$\square$ Prefer not to tell 
Open Access This article is licensed under a Creative Commons Attribution 4.0 International License, which permits use, sharing, adaptation, distribution and reproduction in any medium or format, as long as you give appropriate credit to the original author(s) and the source, provide a link to the Creative Commons licence, and indicate if changes were made. The images or other third party material in this article are included in the article's Creative Commons licence, unless indicated otherwise in a credit line to the material. If material is not included in the article's Creative Commons licence and your intended use is not permitted by statutory regulation or exceeds the permitted use, you will need to obtain permission directly from the copyright holder. To view a copy of this licence, visit http://creativecommons.org/licenses/by/4.0/.

\section{References}

American Psychiatric Association. (2013). Diagnostic and statistical manual of mental disorders (5th ed.). Arlington, VA: Author. https://doi.org/10.1176/appi.books.9780890425596.

Bass, C., \& Halligan, P. (2014). Factitious disorders and malingering: Challenges for clinical assessment and management. The Lancet, 383, 1422-1432. https://doi.org/10.1016/S0140-6736(13)62186-8.

Bass, C., \& Wade, D. T. (2019). Malingering and factitious disorder. Practical Neurology, 19, 96-105. https://doi.org/10.1136/ practneurol-2018-001950.

Berry, D. T., \& Nelson, N. W. (2010). DSM-5 and malingering: A modest proposal. Psychological Injury and Law, 3, 295-303. https://doi. org/10.1007/s12207-010-9087-7.

Bianchini, K. J., Curtis, K. L., \& Greve, K. W. (2006). Compensation and malingering in traumatic brain injury: A dose-response relationship? The Clinical Neuropsychologist, 20, 831-847. https://doi.org/10. 1080/13854040600875203.

Bošković, I. (2019). Do motives matter? A comparison between positive and negative incentives in students' willingness to malinger. In Educational Psychology (pp. 1-11). https://doi.org/10.1080/ 01443410.2019 .1704400 .

Chafetz, M. D., Bauer, R. M., \& Haley, P. S. (2019). The other face of illness-deception: Diagnostic criteria for factitious disorder with proposed standards for clinical practice and research. The Clinical Neuropsychologist, 33, 1-23. https://doi.org/10.1080/13854046. 2019.1663265.

Cohen, Z. E., \& Appelbaum, P. S. (2016). Experience and opinions of forensic psychiatrists regarding PTSD in criminal cases. The Journal of the American Academy of Psychiatry and the Law, 44, $41-52$.

Dandachi-FitzGerald, B., \& Martin, P. K. (in press). Clinical judgment and clinically applied statistics: Description, benefits, and potential danger when relying on either one individually in clinical practice. In R. W. Schroeder \& P. K. Martin (Eds.), Neuropsychological validity assessment in non-forensic clinical practice.

Dandachi-FitzGerald, B., \& Merckelbach, H. (2013). Feigning $\neq$ feigning a memory deficit: The Medical Symptom Validity Test as an example. Journal of Experimental Psychopathology, 4, 46-63. https:// doi.org/10.5127/jep.025511.

Dandachi-FitzGerald, B., Merckelbach, H., \& Ponds, R. W. (2017). Neuropsychologists' ability to predict distorted symptom presentation. Journal of Clinical and Experimental Neuropsychology, 39, 257-264. https://doi.org/10.1080/13803395.2016.1223278.

Dandachi-FitzGerald, B., Ponds, R. W., \& Merten, T. (2013). Symptom validity and neuropsychological assessment: A survey of practices and beliefs of neuropsychologists in six European countries. Archives of Clinical Neuropsychology, 28, 771-783. https://doi. org/10.1093/arclin/act073.
Erdodi, L. A., Hurtubise, J. L., Charron, C., Dunn, A., Enache, A., McDermott, A., \& Hirst, R. (2018). The D-KEFS trails as performance validity tests. Psychological Assessment, 30, 1081-1095. https://doi.org/10.1037/pas0000561.

Hong, V., Pirnie, L., \& Shobassy, A. (2019). Antisocial and borderline personality disorders in the emergency department: Conceptualizing and managing "malingered" or "exaggerated" symptoms. Current Behavioral Neuroscience Reports, 6, 127-132. https://doi.org/10. 1007/s40473-019-00183-4.

Jackson, C. E., Nordstrom, L., Fonda, J. R., Fortier, C. B., Milberg, W. P., \& McGlinchey, R. E. (2017). Reporting of symptoms associated with concussion by $\mathrm{OEF} / \mathrm{OIF} / \mathrm{OND}$ veterans: Comparison between research and clinical contexts. Brain Injury, 31, 485-492. https:// doi.org/10.1080/02699052.2017.1280740.

Jelicic, M., Merckelbach, H., \& Bošković, I. (2017). Seven myths about feigning. In H. Otgaar \& M. L. Howe (Eds.), Finding the truth in the courtroom: Dealing with deception, lies, and memories (pp. 128131). New York: Oxford University Press. https://doi.org/10.1093/ oso/9780190612016.003.0011.

Jung, C. G. (1903). Über simulation von Geistesstörungen [on the simulation of psychopathology]. Journal für Psychologie und Neurologie [Journal of Psychology and Neurology], 5, 181-2012.

Larrabee, G. J., Millis, S. R., \& Meyers, J. E. (2009). 40 plus or minus 10, a new magical number: Reply to Russell. The Clinical Neuropsychologist, 23, 841-849. https://doi.org/10.1080/ 13854040902796735.

Loughran, T. A., Paternoster, R., \& Thomas, K. J. (2014). Incentivizing responses to self-report questions in perceptual deterrence studies: An investigation of the validity of deterrence theory using Bayesian truth serum. Journal of Quantitative Criminology, 30, 677-707. https://doi.org/10.1007/s10940-014-9219-4.

Merckelbach, H., Dandachi-FitzGerald, B., van Helvoort, D., Jelicic, M., \& Otgaar, H. (2019). When patients overreport symptoms: More than just malingering. Current Directions in Psychological Science, 28, 321-326. https://doi.org/10.1177/0963721419837681.

Merten, T., \& Giger, P. (2018). Wie häufig treten Simulation und Aggravation in der Beachtung auf? Schätzungen von Laien. Forensische Psychiatrie, Psychologie, Kriminologie, 12, 164-171.

Merten, T., \& Rogers, R. (2017). An international perspective on feigned mental disabilities: Conceptual issues and continuing controversies. Behavioral Sciences \& the Law, 35, 97-112. https://doi.org/10. $1002 / \mathrm{bsl} .2274$

Mittenberg, W., Patton, C., Canyock, E. M., \& Condit, D. C. (2002). Base rates of malingering and symptom exaggeration. Journal of Clinical and Experimental Neuropsychology, 24, 1094-1102. https://doi. org/10.1076/jcen.24.8.1094.8379.

Niesten, I. J., Nentjes, L., Merckelbach, H., \& Bernstein, D. P. (2015). Antisocial features and "faking bad": A critical note. International Journal of Law and Psychiatry, 41, 34-42. https://doi.org/10.1016/j. ijlp.2015.03.005.

Parsons, T. (1975). The sick role and the role of the physician reconsidered. The Milbank Memorial Fund Quarterly: Health and Society, 53, 257-278. https://doi.org/10.2307/3349493.

Petrie, K. J., Faasse, K., Crichton, F., \& Grey, A. (2014). How common are symptoms? Evidence from a New Zealand national telephone survey. BMJ Open, 4, e005374. https://doi.org/10.1136/bmjopen2014-005374.

Plohmann, A. M., \& Hurter, M. (2017). Prevalence of poor effort and malingered neurocognitive dysfunction in litigating patients in Switzerland. Zeitschrift für Neuropsychologie, 27, 97-116. https:// doi.org/10.1024/1016-264X/a000200.

Santamaría, P., Ramírez, P. C., \& González Ordi, H. (2013). Prevalencia de simulación en incapacidad temporal: percepción de los profesionales de la salud. Clínica y Salud, 24, 139-151. https:// doi.org/10.5093/cl2013a15. 
Sirken, M. G. (1970). Household surveys with multiplicity. Journal of the American Statistical Association, 65, 257-266.

Suchy, Y. (2019). Introduction to special issue: Current trends in empirical examinations of performance and symptom validity. The Clinical Neuropsychologist, 33, 1349-1353. https://doi.org/10. 1080/13854046.2019.1672334.

Suhr, J., \& Wei, C. (2013). Symptoms as an excuse: Attention deficit/ hyperactivity disorder symptom reporting as an excuse for cognitive test performance in the context of evaluative threat. Journal of Social and Clinical Psychology, 32, 753-769. https://doi.org/10. 1521/jscp.2013.32.7.753.

Summerfield, D. (2011). Metropolitan police blues: Protracted sickness absence, ill health retirement, and the occupational psychiatrist. British Medical Journal, 342, 4-19. https://doi.org/10.1136/bmj. d2127.

Tourangeau, R., \& Yan, T. (2007). Sensitive questions in surveys. Psychological Bulletin, 133, 859-883. https://doi.org/10.1037/ 0033-2909.133.5.859.
Van Egmond, J. J., \& Kummeling, I. (2002). A blind spot for secondary gain affecting treatment outcome. European Psychiatry, 17, 46-54. https://doi.org/10.1016/S0924-9338(02)00622-3.

Victor, T. L., Boone, K. B., Serpa, J. G., Buehler, J., \& Ziegler, E. A. (2009). Interpreting the meaning of multiple symptom validity test failure. The Clinical Neuropsychologist, 23, 297-313. https://doi. org/10.1080/13854040802232682.

Young, G. (2015). Malingering in forensic disability-related assessments: Prevalence $15 \pm 15 \%$. Psychological Injury and Law, 8, 188-199. https://doi.org/10.1007/s12207-015-9232-4.

Young, G. (2019). The cry for help in psychological injury and law: Concepts and review. Psychological Injury and Law, 12, 225-237. https://doi.org/10.1007/s12207-019-09360-y.

Publisher's Note Springer Nature remains neutral with regard to jurisdictional claims in published maps and institutional affiliations. 